\title{
Passivity-Based Control for a PV/Battery/Fuel Cell/Electrolyser Hybrid Power System
}

\author{
S. Kong, M. Hilairet, R. Roche \\ FEMTO-ST, CNRS, Univ. Bourgogne Franche-Comte, UTBM \\ FCLAB, CNRS, Univ. Bourgogne Franche-Comte, rue Thierry Mieg, F-90010 Belfort Cedex, France \\ suyao.kong@utbm.fr, mickael.hilairet@univ-fcomte.fr, robin.roche@utbm.fr
}

\begin{abstract}
In this work, a passivity-based controller is proposed for a hybrid system including photovoltaic panels, a fuel cell, a battery and an electrolyser. This short-term controller is designed by the Interconnection and Damping Assignment Passivity Based Control (IDA-PBC) method to solve the converters coordination problem. Simulation results prove that this controller achieves an optimal exploitation of the components while preserving the stability of the whole closed-loop system.
\end{abstract}

Key words-Battery, electrolyser, fuel cell, IDA-PBC methodology, photovoltaic.

\section{INTRODUCTION}

With the increase of world population and rapid industrialization and urbanization, the traditional fossil fuel-based energy sources are no longer sufficient to meet the growing energy demand [1]. In order to deal with the above issues, renewable energies are the main option.

Solar energy is becoming one of the main sources of renewable energy in many countries. However, the production of a photovoltaic power system depends on weather conditions and is therefore intermittent and variable. This induces reliability issues as the balance between generation and demand must be met in real time. Energy storage is commonly used to mitigate these issues. Battery Storage Systems (BSS) are typically used to face short-term (e.g. day-night) variability, while longerterm storage in the form of hydrogen energy may also be used over longer periods. A Hydrogen Energy Storage System (HESS) consists of a fuel cell (FC), a water electrolyser and hydrogen storage tanks. The hydrogen produced by the electrolyser is stored in the tanks and used by the fuel cell when necessary [2].

For the HESS system, Proton Exchange Membrane (PEM) FCs have been found to be especially suitable for such hybrid energy systems among various types of FC systems. This is mainly due to their high power density as well as low operating temperature [3]. Unfortunately, the lifetime of PEMFC systems is limited by multiple impairments. Premature aging of PEMFCs is indeed observed during abrupt load current changes. As a consequence, PEMFCs are generally associated with auxiliary components to reduce the variability of the FC current. In the considered system, the FC is the main controllable power source, and is associated to a battery [4][7] to smooth the current. Alternatively, the FC can also be associated with super-capacitors [8]-[12].
Several types of controllers with high-performance were proposed in the literature. They are based on different methodologies, such as fuzzy logic [10], Model Predictive Control (MPC) [7] or load sharing [13]. These controllers typically aim to achieve an optimal energy management strategy to meet the demand of the load while avoiding high dynamic power from the FC. However, the stability of the closed-loop system is not always proved theoretically in these researches.

To address this problem, in this paper, the Interconnection and Damping Assignment - Passivity Based Control (IDAPBC) method [14]-[16] is applied for the controller design. Compared with other methods, the main advantage of IDAPBC is the theoretical proof of the stability of the whole closed-loop system, associated with a high-performance coordination of all components.

Unlike a short-term dispatcher that gives the solution of Economic Dispatch (ED) to minimize the cost, the controller proposed in this work aims at solving the converters coordination problem and ensuring stability by considering the realtime condition of the system. In a real system, it would be combined with other, longer term algorithms (e.g., a day-ahead scheduler), as a part of the energy management system (EMS) in a microgrid.

There are four sections in this paper: Section II describes the modeling of the hybrid system; then the controller design using IDA-PBC is detailed in section III; Section IV introduces the power management strategy in different cases of operation; finally, the results are provided in Section V.

\section{CONTROL STRUCTURE AND HYBRID SYSTEM MODEL}

In this section, the modeling of the different components and of the hybrid system are presented.

\section{A. Elements models}

A static model of the fuel cell [17] is employed, which is described by a $5^{t h}$ order polynomial function:

$v_{f c}(t)=a_{5} i_{f c}^{5}(t)+a_{4} i_{f c}^{4}(t)+a_{3} i_{f c}^{3}(t)+a_{2} i_{f c}^{2}(t)+a_{1} i_{f c}(t)+a_{0}$

where coefficients $a_{i}(i \in[0,5])$ were determined based on real current/voltage measurements on an experimental FC [18]. 


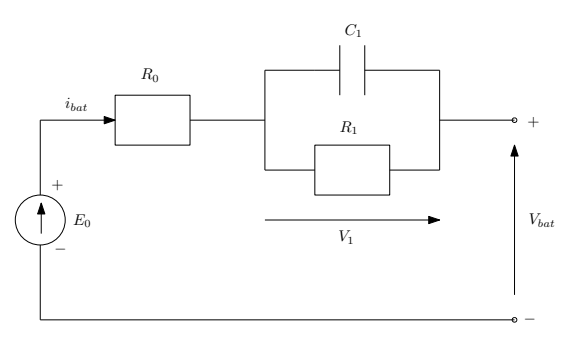

Fig. 1. Diagram for the Thevenin model of the battery

The battery is modeled by a first order equivalent circuit [19]. The diagram for the Thevenin model can be seen in Fig. 1. Mathematically, the battery is modeled as follows:

$$
\begin{aligned}
v_{b a t}(t) & =E_{0}(S o C(t))-v_{1}(t)-R_{0} i_{\text {bat }}(t) \\
\frac{d}{d t} v_{1}(t) & =-\frac{v_{1}(t)}{R_{1} C_{1}}+\frac{i_{b a t}(t)}{C_{1}}
\end{aligned}
$$

In this model, the internal resistance of the battery includes the ohmic resistance $R_{0}$ and the polarization resistance $R_{1}$. The equivalent capacitance $C_{1}$ describes the transient response during charging and discharging of the battery. $E_{0}$ is the opencircuit voltage which depends on the state-of-charge $(\mathrm{SoC})$ as described by a $4^{\text {th }}$ order polynomial function:

$E_{0}(t)=b_{4} S o C^{4}(t)+b_{3} S o C^{3}(t)+b_{2} S o C^{2}(t)+b_{1} S o C(t)+b_{0}$

where coefficients $b_{i}(i \in[0,4])$ were determined based on real current/voltage measurements on an experimental battery IHR-18650(NMC) at $25^{\circ} \mathrm{C}$ [20].

A model of a PEM water electrolyser is applied from [21], where the single cell output voltage is composed of several parts as follows:

$$
v_{\text {elec }}(t)=E_{\text {rev }}^{a}+E_{\text {rev }}^{c}+v_{a}(t)+v_{c}(t)+R_{\text {elec }} i_{\text {el }} \text { den }(t)
$$

In this model, $a$ represents the anode and $c$ represents the cathode. $E_{r e v}$ is the reversible potential of the both electrodes, $v_{a}$ and $v_{c}$ are the over potential of each electrode, $R_{\text {elec }}$ is the internal resistance of the cell and $i_{e l_{d e n}}$ is the current density in $\mathrm{A} / \mathrm{cm}^{2}$. In this work, since the cathode could be ignored, only the anode side is considered. Then the model is simplified as:

$$
v_{\text {elec }}(t)=E_{\text {rev }}^{a}+v_{a}(t)+R_{\text {elec }} i_{e l_{\text {den }}}(t)
$$

The temperature is set at $80^{\circ} \mathrm{C}$ with 10 cells in series in an electrolyser stack.

The PV system model is based on [22]. The PV voltagecurrent characteristic of a cell is described by the following equation:

$$
i_{p v}(t)=i_{p h}(G(t))-i_{s}(t) e^{\left(\frac{q v_{p v}(t)}{k T_{c} A}-1\right)}
$$

where $i_{p h}(t)$ is the photo-current generated by solar light $G(t)$, $i_{s}(t)$ is the cell saturation of dark current, $q$ is an electron charge, $k$ is the Boltzmann's constant, $T_{c}$ is the working temperature of the cell, and $A$ is an ideal factor. For one PV module, there are 36 cells in series and one cell in parallel.

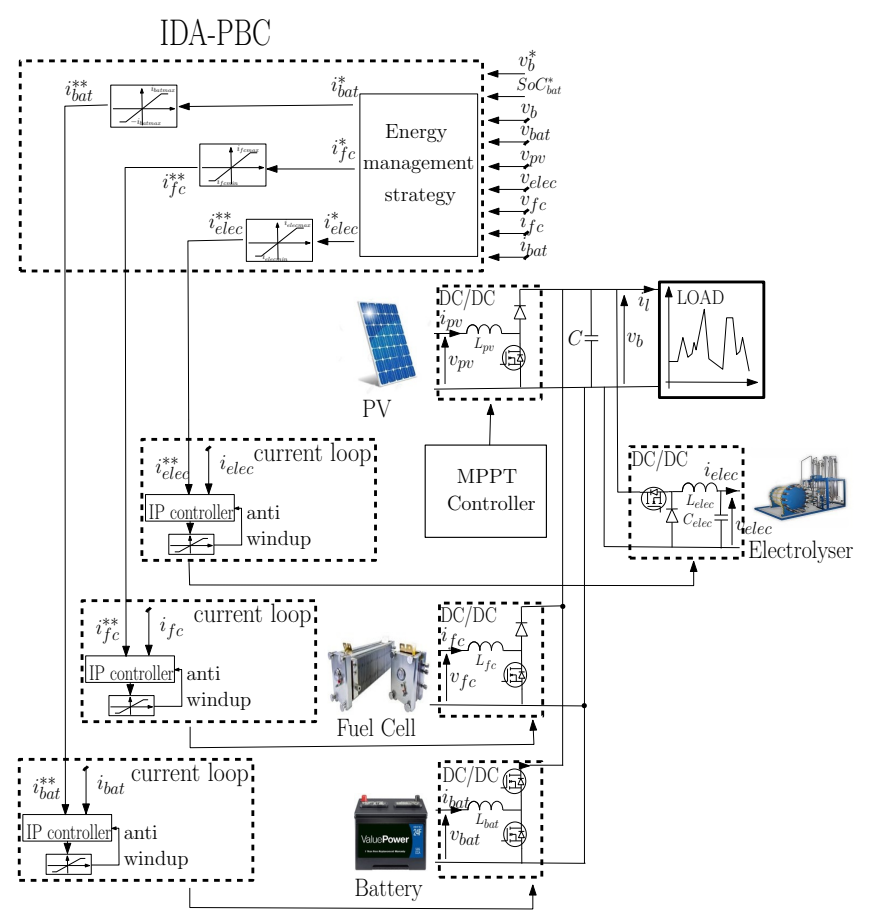

Fig. 2. System structure and control architecture

In this research, the hybrid system consists of one PV module $(425 \mathrm{~W})$, one fuel cell stack $(1.2 \mathrm{~kW})$, one electrolyser stack $(925 \mathrm{~W})$, and 6 battery packs of $1.6 \mathrm{Ah}$ in series.

\section{B. Hybrid system modeling}

There are three types of electrical architectures for a hybrid system: series, parallel and cascades [23]. In this research, the parallel architecture is applied. Batteries are connected to the DC bus through a reversible boost converter so that the batteries can charge or discharge according to the load power, the PV power production and the $\mathrm{SoC}$ of the batteries. The PV and FC are connected with two DC/DC boost converters while the electrolyser is connected with a DC/DC buck converter. Fig. 2 shows the simplified hybrid system structure as well as the architecture of the power management control, where all the electrical elements are connected in parallel to the DC bus, through static converters.

The controller consists of fast inner current control loops and slow outer voltage loops, in order to protect the equipment. The current loops are based on IP controllers while the control of DC bus voltage and battery SoC is realized by the voltage loops. They are designed based on the IDA-PBC method described in the next sections.

The complete system is represented by the following $6^{\text {th }}$ order nonlinear state space model:

$$
\begin{aligned}
\frac{d}{d t} v_{b}(t) & =\frac{1}{C}\left[\left(1-\alpha_{1}(t)\right) i_{f c}(t)\right. \\
& +\left(1-\alpha_{2}(t)\right) i_{b a t}(t)+\left(1-\alpha_{3}(t)\right) i_{p v}(t) \\
& \left.-\alpha_{4}(t) i_{\text {elec }}(t)-i_{l}(t)\right] \\
\frac{d}{d t} v_{1}(t) & =-\frac{v_{1}(t)}{R_{1} C_{b a t}}+\frac{i_{b a t}(t)}{C_{b a t}}
\end{aligned}
$$




$$
\begin{aligned}
\frac{d}{d t} i_{f c}(t) & =\frac{-\left(1-\alpha_{1}(t)\right) v_{b}(t)+v_{f c}(t)}{L_{f c}} \\
\frac{d}{d t} i_{b a t}(t) & =\frac{-\left(1-\alpha_{2}(t)\right) v_{b}(t)+v_{b a t}(t)}{L_{b a t}} \\
\frac{d}{d t} i_{p v}(t) & =\frac{-\left(1-\alpha_{3}(t)\right) v_{b}(t)+v_{p v}(t)}{L_{p v}} \\
\frac{d}{d t} i_{\text {elec }}(t) & =\frac{\alpha_{4}(t) v_{b}(t)-v_{\text {elec }}(t)}{L_{\text {elec }}}
\end{aligned}
$$

with state space $x(t)=\left[v_{b} ; v_{1} ; i_{f c} ; i_{b a t} ; i_{p v} ; i_{e l e c}\right]^{T}$, control inputs $u(t)=\left[u_{1} ; u_{2} ; u_{3} ; u_{4}\right]^{T}=\left[1-\alpha_{1} ; 1-\alpha_{2} ; 1-\right.$ $\left.\alpha_{3} ; \alpha_{4}\right]^{T}$, and measurements $y(t)=x(t), v_{f c}(t)$ and $v_{\text {elec }}(t)$.

Here, the duty cycles of the converters are represented by $\alpha_{1,2,3,4}(t)$. Variables $v_{b}(t), v_{f c}(t), v_{p v}(t)$ and $v_{e l e c}(t)$ are the voltages of the DC bus, FC, PV and of the electrolyser. $v_{1}(t)$ is the voltage across $C_{1}$ and $R_{1}$ in the Thevenin model. $i_{f c}(t)$, $i_{\text {bat }}(t), i_{p v}(t), i_{\text {elec }}(t)$ are the current of the FC, battery, PV and electrolyser, and $i_{l}(t)$ is the DC current delivered to the load.

The IP current controllers are supposed to force the current $i$ to track their references $i^{*}$. In order to simplify the design of the outer control loops, we assume that $L_{f c}, L_{b a t}, L_{p v}$, and $L_{\text {elec }}$ are small compared to the other parameters. Therefore, due to the difference of time scale between the voltages and the currents (called singular perturbed system [14]), we can assume that all the current are equal to the references. So the system can be represented by a $2^{\text {nd }}$ order nonlinear state space model as follows:

$$
\begin{aligned}
\frac{d}{d t} v_{b}(t) & =\frac{1}{C}\left[\frac{v_{f c}(t)}{v_{b}(t)} i_{f c}^{*}(t)+\frac{v_{b a t}(t)}{v_{b}(t)} i_{b a t}^{*}(t)\right. \\
& \left.+\frac{v_{p v}(t)}{v_{b}(t)} i_{p v}(t)-\frac{v_{\text {elec }}(t)}{v_{b}(t)} i_{\text {elec }}^{*}(t)-i_{l}(t)\right] \\
\frac{d}{d t} v_{1}(t) & =-\frac{v_{1}(t)}{R_{1} C_{1}}+\frac{i_{b a t}^{*}(t)}{C_{1}}
\end{aligned}
$$

with $x_{r}(t)=\left[x_{1} ; x_{2}\right]^{T}=\left[v_{b} ; v_{1}\right]^{T}$, control inputs $u_{r}=\left[i_{f c}^{*} ; i_{b a t}^{*} ; i_{\text {elec }}^{*}\right]^{T}$, measurements $y_{r}=\left[v_{b} ; v_{1}\right]^{T}$ and $z_{r}=\left[i_{f c} ; i_{\text {bat }} ; i_{p v} ; i_{\text {elec }} ; v_{f c} ; v_{b a t} ; v_{\text {elec }} ; v_{p v}\right]^{T}$.

\section{Controller Design USING IDA-PBC}

In this section, the design of the IDA-PBC-based controller for the studied system is described.

\section{A. Introduction}

The IDA-PBC method consists in finding a static statefeedback control $u(x)=\theta(x)$ such that the closed-loop dynamics is a Port-Controlled Hamiltonian (PCH) system with the interconnection and the dissipation of the form:

$$
\dot{x}=\left[\mathcal{J}_{d}(x)-\mathcal{R}_{d}(x)\right] \nabla \mathcal{H}_{d}
$$

where $\mathcal{H}_{d}(x)$ is the natural energy function of the system, $J_{d}(x)$ is a skew-symmetric matrix of dimension $n \times n$ representing the interconnections between states, and $R_{d}(x)$ is a positive semi-definite symmetric matrix representing the natural damping of the system.
The first step of the design procedure is to rewrite the nonlinear system

$$
\begin{aligned}
& \dot{x}=f(x)+g(x) u ; \quad x \in \Re^{n} ; u \in \Re^{m} \\
& y=h(x) ; \quad y \in \Re^{m}
\end{aligned}
$$

versus the gradient of the energy function

$$
\nabla \mathcal{H}(x)=\left[\begin{array}{llll}
\frac{\partial \mathcal{H}}{\partial x_{1}}(x) & \frac{\partial \mathcal{H}}{\partial x_{2}}(x) & \ldots & \frac{\partial \mathcal{H}}{\partial x_{n}}(x)
\end{array}\right]^{T}
$$

so that the $\mathrm{PCH}$ form of the nonlinear system is

$$
\begin{aligned}
\dot{x} & =[\mathcal{J}(x)-\mathcal{R}(x)] \mathcal{H}(x)+g(x) u \\
y & =g^{T}(x) \nabla \mathcal{H}(x)
\end{aligned}
$$

where $y$ is the output, $\mathcal{J}(x)=-\mathcal{J}^{T}(x)$ is a skew-symmetric matrix of dimension $n \times n$ representing the interconnections between states, and $\mathcal{R}(x)=\mathcal{R}^{T}(x) \geq 0$ is a positive semidefinite symmetric matrix representing the natural damping of the system.

Assume that there is a function $H_{d}(x): \Re^{n} \longrightarrow \Re$ and there are matrices $\mathcal{J}_{d}(x)=-\mathcal{J}_{d}^{T}(x), \mathcal{R}_{d}(x)=\mathcal{R}_{d}^{T}(x) \geq 0$, with which the closed-loop system with control variable

$$
u=\left[g^{T}(x) g(x)\right]^{-1} g^{T}(x)\left\{\left[\mathcal{J}_{d}(x)-\mathcal{R}_{d}(x)\right] \nabla \mathcal{H}_{d}-f(x)\right\}
$$

takes the initial system to the PCH form

$$
\dot{x}=\left[\mathcal{J}_{d}(x)-\mathcal{R}_{d}(x)\right] \nabla \mathcal{H}_{d}
$$

where $x^{*}=\operatorname{argmin}_{\mathrm{x} \in \Re^{\mathrm{n}}}\left(\mathcal{H}_{\mathrm{d}}(\mathrm{x})\right)$ with $x^{*} \in \Re^{n}$ the (local) equilibrium to be stabilized. The system is asymptotically stable if:

- $x^{*}$ is an isolated minimum of $\mathcal{H}_{d}(x)$

- the largest invariant set under the closed-loop dynamics (21) contained in $\left\{x \in \Re^{n} \mid\left[\nabla H_{d}\right]^{T} \mathcal{R}_{d}(x) \nabla \mathcal{H}_{d}=0\right\}$ equals $x^{*}[18]$.

From the trajectories of (21), we have

$$
\dot{\mathcal{H}}_{d}=-\left[\nabla \mathcal{H}_{d}\right]^{T} \mathcal{R}_{d}(x) \nabla \mathcal{H}_{d} \leq 0
$$

Therefore, $\mathcal{H}_{d}(x)$ is qualified as a Lyapunov function and the closed-loop system is asymptotically stable.

\section{B. Controller design}

The aim of IDA-PBC is to assign the state point $x_{r}$ to the desired equilibrium one $x_{r}^{*}$, with the DC bus and battery desired voltages $v_{b}^{*}$ and $v_{1}^{*}$ as target.

$$
\begin{aligned}
& x_{r}=\left[x_{1} ; x_{2}\right]^{T}=\left[v_{b} ; v_{1}\right]^{T} \\
& x_{r}^{*}=\left[v_{b}^{*} ; v_{1}^{*}\right]
\end{aligned}
$$

where $v_{1}^{*}(t)=E_{0}(S o C(t))-v_{b a t}^{*}-R_{0} i_{b a t}(t)$ using equ. 2 and 4 .

In this research, the energy function $\mathcal{H}_{d}$, which is a Lyapunov function, is chosen as follows:

$$
\mathcal{H}_{d}=\frac{1}{2} \tilde{x}_{r}^{T} Q \tilde{x}_{r}
$$

with $\tilde{x}_{r}=x_{r}-x_{r}^{*}$ and $Q=\operatorname{diag}\left(\mathrm{C}, \mathrm{C}_{1}\right)$. 
Then the PCH system can be expressed as follows, with the error and the gradient of the desired closed-loop energy function:

$$
\dot{\tilde{x}}_{r}=[\mathcal{J}-\mathcal{R}] \nabla \mathcal{H}_{d}+A\left(u_{r}, x_{r}, x_{r}^{*}, z_{r}\right)
$$

where:

$$
\begin{gathered}
\mathcal{J}-\mathcal{R}=\left[\begin{array}{ll}
0 & 0 \\
0 & 0
\end{array}\right], \quad \nabla \mathcal{H}_{d}=\left[\begin{array}{c}
C \tilde{v}_{b} \\
C_{1} \tilde{v}_{1}
\end{array}\right] \\
A=\left[\begin{array}{c}
\frac{1}{C}\left[\frac{v_{f c}(t)}{v_{b}(t)} i_{f c}^{*}(t)+\frac{v_{b a t}(t)}{v_{b}(t)} i_{b a t}^{*}(t)+\frac{v_{p v}(t)}{v_{b}(t)} i_{p v}(t)\right. \\
\left.-\frac{v_{e l e c}(t)}{v_{b}(t)} i_{\text {elec }}^{*}(t)-i_{l}(t)\right] \\
-\frac{v_{1}(t)}{R_{1} C_{1}}+\frac{i_{b a t}^{*}(t)}{C_{1}}
\end{array}\right]
\end{gathered}
$$

In order to solve the algebraic equation in $\mathcal{J}_{d}(x)$ and $\mathcal{R}_{d}(x)$ with

$$
\mathcal{J}_{d}=\left[\begin{array}{cc}
0 & J_{12} \\
-J_{12} & 0
\end{array}\right], \quad \mathcal{R}_{d}=\left[\begin{array}{cc}
r_{1} & 0 \\
0 & r_{2}
\end{array}\right]
$$

Equ. 21 and 25 need to be equal, the nonlinear control law is determined as follows:

$$
\begin{aligned}
\delta \dot{y}(t) & =-y(t)+i_{l}(t) / v_{b}(t) ; \quad \delta>0 \\
\frac{v_{f c}(t)}{v_{b}(t)} i_{f c}^{*}(t) & -\frac{v_{\text {elec }}(t)}{v_{b}(t)} i_{\text {elec }}^{*}(t) \\
& =y(t) v_{b}^{*}-\frac{v_{p v}(t)}{v_{b}(t)} i_{p v}(t)-\frac{v_{b a t}(t)}{v_{b}(t)} \frac{v_{1}(t)}{R_{1}} \\
& +C_{1}\left(C J_{12}+\frac{v_{b a t}(t)}{v_{b}(t)} C_{1} r_{2}\right) \tilde{v}_{1}(t) \\
& +C\left(\frac{v_{b a t}(t)}{v_{b}(t)} C_{1} J_{12}-r_{1} C\right) \tilde{v}_{b}(t) \\
i_{b a t}^{*}(t) & =\frac{v_{1}(t)}{R_{1}}-C_{1}\left(C J_{12} \tilde{v}_{b}(t)+r_{2} C_{1} \tilde{v}_{1}(t)\right)
\end{aligned}
$$

where the load current $i_{l}$ has been replaced by $y v_{b}^{*}$, i.e., an admittance estimator multiplied by the desired voltage of the DC bus [8].

In this work, the general non-linear controller has been refined tacking into the following constraints:

- In the case of normal operation, the battery SoC is within the range of $[30 \%, 90 \%]$, there is no limitation of the FC and battery currents, so $r_{2}$ is set to zero. Moreover, the FC and electrolyser have to manage the SoC of the battery, without a direct action of the DC bus voltage. So we have:

$$
\frac{v_{b a t}}{v_{b}} \alpha-r_{1} C^{2}=0
$$

which leads to $r_{1}=\frac{v_{s c} \alpha}{v_{b} C^{2}}$ by setting $C_{1} C J_{12}=\alpha$, with $\alpha>0$.

- Considering that the inner voltage of the battery $v_{1}$ is non measurable, we have $\tilde{v}_{1}=-\tilde{v}_{\text {bat }}$ based on equ. 2 and $v_{1}$ is estimated online based on equ. 3 .
Finally, based on the above constrains, the control law is now as follows:

$$
\begin{aligned}
\delta \dot{y}(t) & =-y(t)+i_{l}(t) / v_{b}(t) ; \quad \delta>0 \\
\dot{v}_{1}(t) & =-\frac{v_{1}(t)}{R_{1} C_{1}}+\frac{i_{\text {bat }}^{*}(t)}{C_{1}} \\
\frac{v_{f c}(t)}{v_{b}(t)} i_{f c}^{*}(t) & -\frac{v_{\text {elec }}(t)}{v_{b}(t)} i_{\text {elec }}^{*}(t)=y(t) v_{b}^{*}-\frac{v_{p v}(t)}{v_{b}(t)} i_{p v}(t) \\
& -\frac{v_{b a t}(t)}{v_{b}(t)} \frac{v_{1}(t)}{R_{1}}-\alpha \tilde{v}_{b a t} \\
i_{b a t}^{*}(t) & =\frac{v_{1}(t)}{R_{1}}-\alpha \tilde{v}_{b}(t)
\end{aligned}
$$

It is clear that the FC and EL are not supposed to work at the same time. So that the FC or EL will be activated in different case according to the production of PV and consumption of the load.

1) Case where $P_{l}>P_{p v}$ : When the load power is greater than the power produced by the PV panels, it follows that the electrolyser is not engaged and the controller (equ. 32) is now:

$$
\begin{aligned}
i_{\text {elec }}^{*}(t) & =0 \\
i_{f c}^{*}(t) & =\frac{v_{b}(t)}{v_{f c}(t)}\left(y(t) v_{b}^{*}-\frac{v_{p v}(t)}{v_{b}(t)} i_{p v}(t)\right. \\
& \left.-\frac{v_{b a t}(t)}{v_{b}(t)} \frac{v_{1}(t)}{R_{1}}-\alpha \tilde{v}_{b a t}(t)\right)
\end{aligned}
$$

2) Case where $P_{l}<P_{p v}$ : When the load power is lower than the power produced by the PV panels, it follows that the electrolsyer is engaged and the FC is stopped. The controller (equ. 32) is now:

$$
\begin{aligned}
i_{f c}^{*}(t) & =0 \\
i_{\text {elec }}^{*}(t) & =-\frac{v_{b}(t)}{v_{\text {elec }}(t)}\left(y(t) v_{b}^{*}-\frac{v_{p v}(t)}{v_{b}(t)} i_{p v}(t)\right. \\
& \left.-\frac{v_{\text {bat }}(t)}{v_{b}(t)} \frac{v_{1}(t)}{R_{1}}-\alpha \tilde{v}_{b a t}(t)\right)
\end{aligned}
$$

\section{Simulation RESUlts}

The system was modeled and simulations were run using Matlab/Simulink. Fig. 3 shows the power curves of the simulation and Fig. 4 presents the detail of the voltage and current of each element. In this simulation, we assume that the PV output power always tracks its maximum point, with the variation of the input solar irradiance $G(t)$.

At the beginning of the simulation, the battery SoC is at the reference level (i.e., at 80\%), and there is no power demand from the load while the PV system is generating energy. Therefore, the FC is not activated and the electrolyser is started during the first $5 \mathrm{~s}$ until the load current increases.

We can also notice that the load operates as a generator from $35 \mathrm{~s}$ to $40 \mathrm{~s}$. In reality, this may happen when the load is an electrical motor. It follows that the FC is stopped, while the battery starts charging and the electrolyser is producing hydrogen.

Since the interconnections between each element are considered in the control law, we can notice that the FC supplies 
the energy that the PV cannot produce at steady state while the battery response quickly during load power transients to stabilize the DC bus voltage (Fig. 4.a), thanks to the term $\alpha \tilde{v}_{b}(t)$ in the control law of battery reference current equ. 33. This is the reason why FC has a smooth response, which increases the FC's lifetime. The electrolyser produces hydrogen using extra energy when the FC is stopped or when the battery cannot absorb power due to its high SoC, according to equ. 37.

In conclusion, the DC bus voltage is kept around its reference value and the optimum response of the system stability is realized by the controller.

\section{CONCLUSION}

In this paper, a short-term controller is designed to manage the energy between PV, hydrogen fuel cell, battery and electrolyser. Compared with other methods, the main advantage of IDA-PBC is that the stability of the closed-loop system is proven theoretically while enabling a smooth response from the FC with fast load demand changes. In addition, this controller has only two parameters to set ( $\alpha$ and $\delta$ ), which makes the configuration easily. Finally, the simulation results show that the controller proposed in this work achieves the integrity and an optimal exploitation of the components automatically while preserving the locally asymptotic stability of the whole closed-loop system. For the future work, the application of this controller on a real distribution grid profile will be tested.

\section{ACKNOWLEDGEMENT}

This work is supported by the ANR DATAZERO project (contract ANR-15-CE25-0012). https://www.irit.fr/datazero.

\section{REFERENCES}

[1] R. Logesh et al., "Resources, configurations, and soft computing techniques for power management and control of pv/wind hybrid system," Renewable and Sustainable Energy Reviews, vol. 69, pp. 129-143, 2017.

[2] A. Ganeshan, D. Holmes, L. Meegahapola, and B. McGrath, "Enhanced control of a hydrogen energy storage system in a microgrid," in Universities Power Engineering Conference (AUPEC), 2017 Australasian. IEEE, 2017, pp. 1-6.

[3] M. Uzunoglu and M. Alam, "Dynamic modeling, design and simulation of a pem fuel cell/ultra-capacitor hybrid system for vehicular applications," Energy Conversion and Management, vol. 48, no. 5, pp. 1544 $1553,2007$.

[4] A. Tofighi and M. Kalantar, "Passivity-based control of pem fuel cell/battery hybrid power source," in Energy conversion congress and exposition (ECCE), 2011 IEEE. IEEE, 2011, pp. 902-908

[5] M. Becherif, "Passivity-based control of hybrid sources: fuel cell and battery," IFAC Proceedings Volumes, vol. 39, no. 12, pp. 585-590, 2006.

[6] J. P. Torreglosa, P. Garcia, L. M. Fernandez, and F. Jurado, "Predictive control for the energy management of a fuel-cell-battery-supercapacitor tramway," IEEE Transactions on Industrial Informatics, vol. 10, no. 1, pp. 276-285, 2014

[8] M. Hilairet, M. Ghanes, O. Béthoux, V. Tanasa, J.-P. Barbot, and D. Normand-Cyrot, "A passivity-based controller for coordination of converters in a fuel cell system," Control engineering practice, vol. 21, no. 8, pp. 1097-1109, Aug. 2013, Control Engineering Practice best application paper prize for years 2011 to 2013 .
[7] R. T. Bambang, A. S. Rohman, C. J. Dronkers, R. Ortega, A. Sasongko et al., "Energy management of fuel cell/battery/supercapacitor hybrid power sources using model predictive control," IEEE Transactions on Industrial Informatics, vol. 10, no. 4, pp. 1992-2002, 2014.

[9] Kong, S and Hilairet, $\mathrm{M}$ and Roche, R, "Advanced Passivity-Based Control for a Fuel Cell/Super-Capacitor Hybrid Power System," in 2017 IEEE Vehicle Power and Propulsion Conference (VPPC). IEEE, 2017, pp. $1-6$.

[10] M. Mohammedi, O. Kraa, M. Becherif, A. Aboubou, M. Ayad, and M. Bahri, "Fuzzy logic and passivity-based controller applied to electric vehicle using fuel cell and supercapacitors hybrid source," Energy Procedia, vol. 50, pp. 619-626, 2014.

[11] P. Thounthong, P. Tricoli, and B. Davat, "Performance investigation of linear and nonlinear controls for a fuel cell/supercapacitor hybrid power plant," International Journal of Electrical Power \& Energy Systems, vol. 54, pp. 454-464, 2014

[12] H. El Fadil, F. Giri, J. M. Guerrero, and A. Tahri, "Modeling and nonlinear control of a fuel cell/supercapacitor hybrid energy storage system for electric vehicles," IEEE Transactions on Vehicular Technology, vol. 63, no. 7, pp. 3011-3018, 2014.

[13] G. T. Samson, T. M. Undeland, O. Ulleberg, and P. J. Vie, "Optimal load sharing strategy in a hybrid power system based on pv/fuel cell/battery/supercapacitor," in Clean Electrical Power, 2009 International Conference on. IEEE, 2009, pp. 141-146.

[14] B. Amrouche, T. O. Cherif, M. Ghanes, and K. Iffouzar, "A passivitybased controller for coordination of converters in a fuel cell system used in hybrid electric vehicle propelled by two seven phase induction motor," International Journal of Hydrogen Energy, 2017.

[15] S. Mane, F. Kazi, and N. Singh, "Fuel cell and ultra-capacitor based hybrid energy control using ida-pbc methodology," in Industrial Instrumentation and Control (ICIC), 2015 International Conference on. IEEE, 2015, pp. 879-884.

[16] F. Yang, B. Sheng, and Y. Fu, "Energy management for fuel cellsupercapacitor hybrid system using passivity-based controller with multi-equilibrium states," in Industrial Electronics Society, IECON 2015-41st Annual Conference of the IEEE. IEEE, 2015, pp. $000511-$ 000516.

[17] H. Peng and A. G. Stefanopoulou, "Control-oriented modeling and analysis for automotive fuel cell systems," Journal of dynamic systems, measurement, and control, vol. 126, pp. 14-25, 2004.

[18] M. Hilairet, M. Ghanes, O. Béthoux, V. Tanasa, J. Barbot, and D. Normand-Cyrot, "A passivity-based controller for coordination of converters in a fuel cell system," Control engineering practice, vol. 21 , no. 8, pp. 1097-1109, 2013.

[19] H. He, R. Xiong, and J. Fan, "Evaluation of lithium-ion battery equivalent circuit models for state of charge estimation by an experimental approach," Energies, vol. 4, no. 4, pp. 582-598, 2011.

[20] P. Saenger, M.-C. Pera, F. Gustin, R. Couturier, and K. Deschinkel, "Emulation of the Operation of a Lithium-Ion Batteries Pack in Healthy and Faulty Condition," 2017 IEEE Vehicle Power and Propulsion Conference (VPPC), 2017.

[21] M. Chandesris, V. Médeau, N. Guillet, S. Chelghoum, D. Thoby, and F. Fouda-Onana, "Membrane degradation in pem water electrolyzer: Numerical modeling and experimental evidence of the influence of temperature and current density," International Journal of Hydrogen Energy, vol. 40, no. 3, pp. 1353-1366, 2015.

[22] H.-L. Tsai, C.-S. Tu, Y.-J. Su et al., "Development of generalized photovoltaic model using matlab/simulink," in Proceedings of the world congress on Engineering and computer science, vol. 2008. San Francisco, USA, 2008, pp. 1-6.

[23] P. Thounthong, S. Raél, and B. Davat, "Control strategy of fuel cell/supercapacitors hybrid power sources for electric vehicle," Journal of Power Sources, vol. 158, no. 1, pp. 806-814, 2006. 


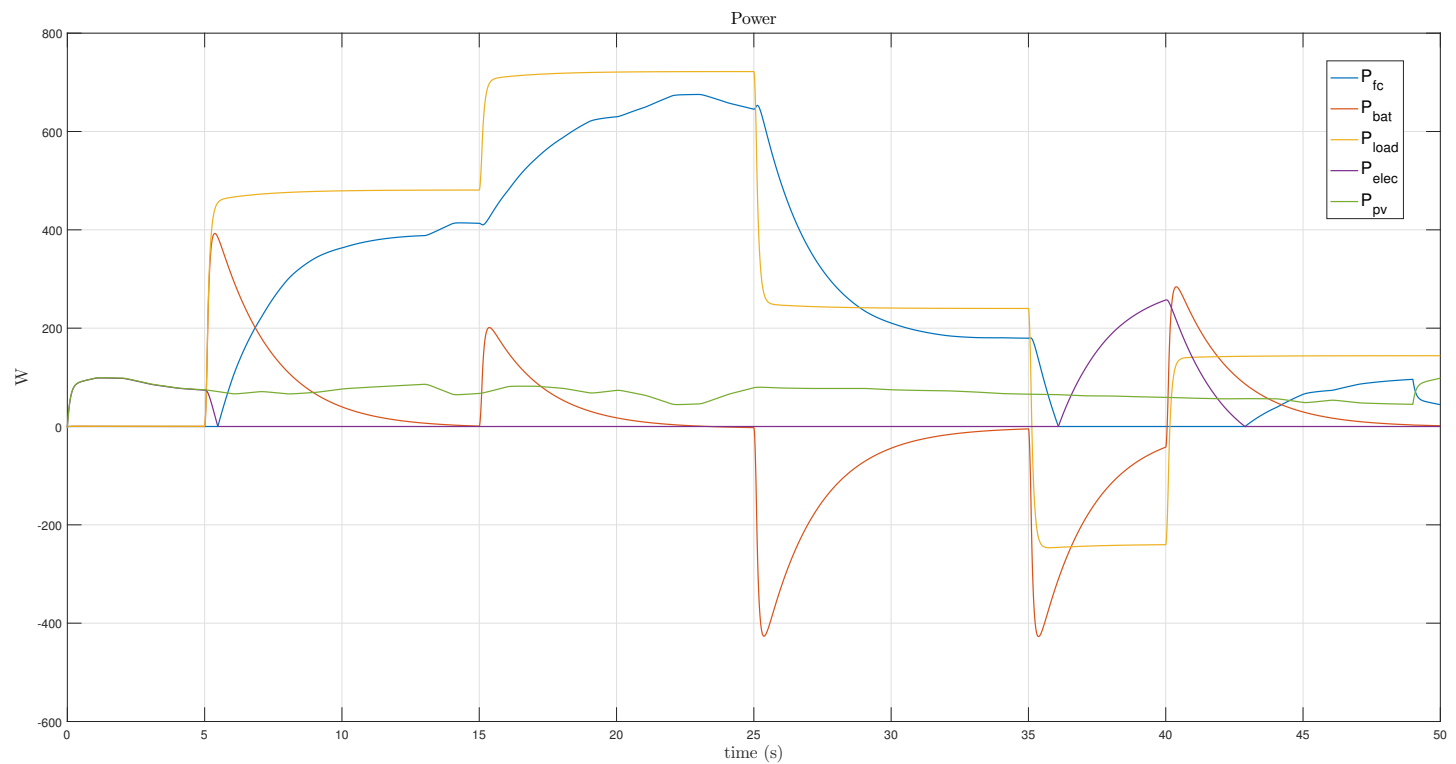

Fig. 3. Power curves

(a) bus voltage $v_{b}$

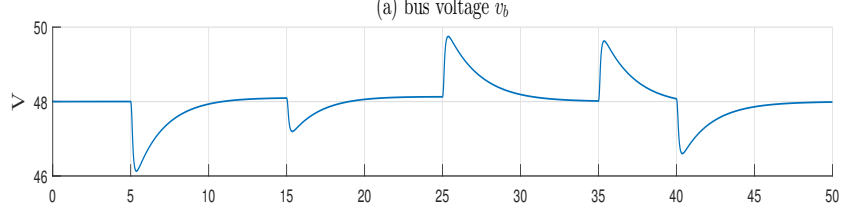

(c) PV voltage $v_{p v}$

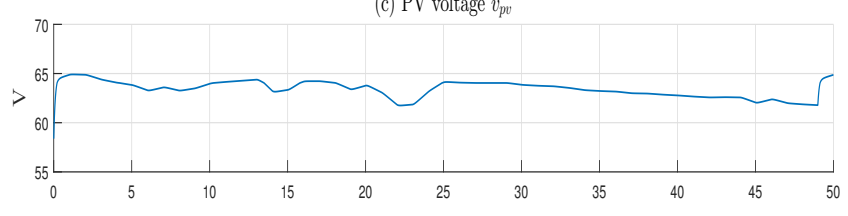

(e) fuel cell voltage $v_{f c}$

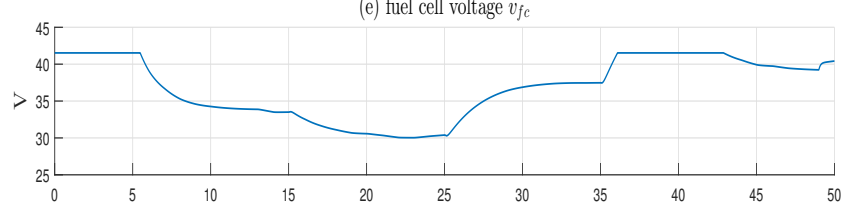

(g) battery voltage $v_{\text {bat }}$

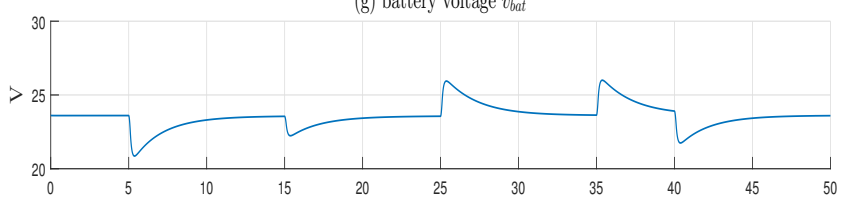

(i) electrolyser voltage $v_{\text {elec }}$

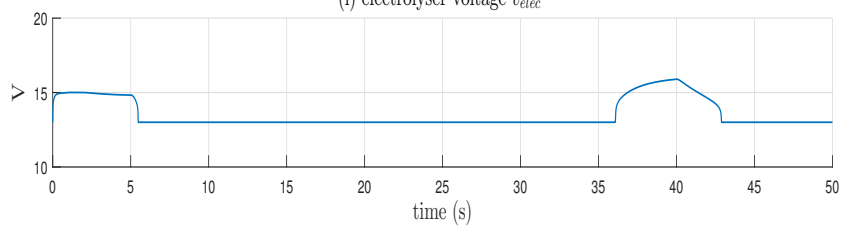

(b) load current $i_{L}$

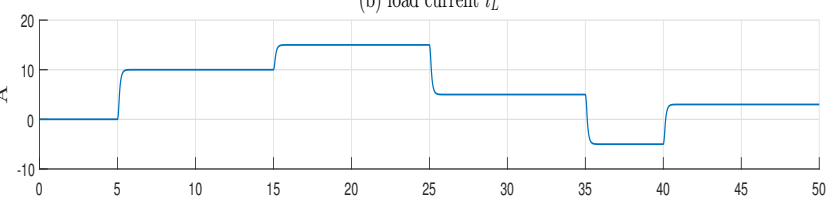

(d) PV current $i_{p v}$

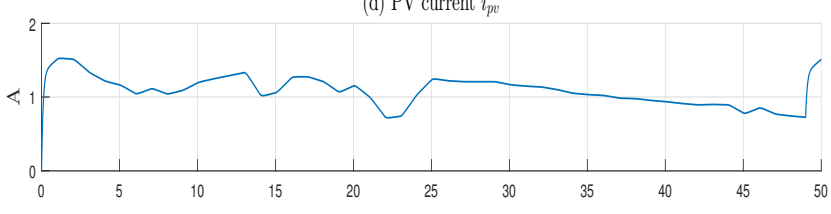

(f) fuel cell current $i_{f c}$

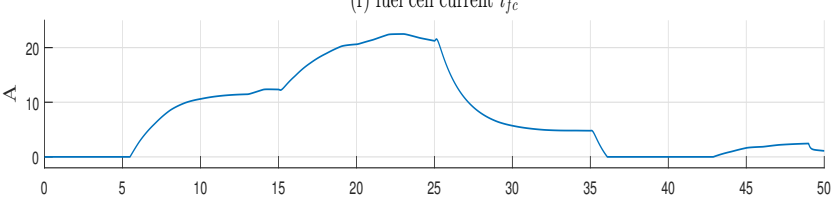

(h) battery current $i_{\text {bat }}$

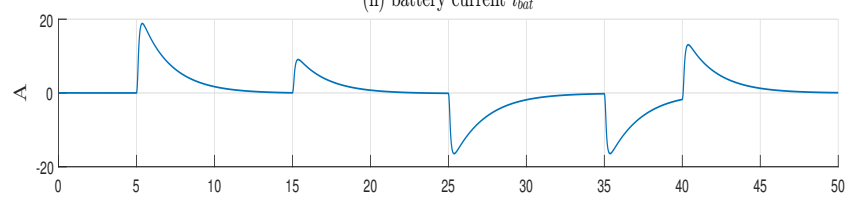

(j) electrolyser current $i_{\text {elec }}$

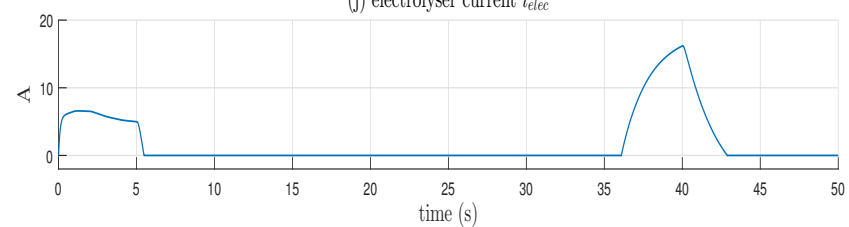

Fig. 4. Voltage and current curves 